\title{
Employer Branding: $O$ que as melhores empresas têm para atrair seus funcionários
}

Employer Branding: What the best companies have to attract their employees

Érika Mirian $\operatorname{Nogas}^{1}\left(\mathbb{D}\right.$, Fernanda Moreti de Souza ${ }^{2}(\mathbb{D}$

${ }^{1}$ Pontifícia Universidade Católica do Paraná (PUCPR), Brasil, Mestre em Administração (PUCPR), e-mail: erika_nogas@hotmail.com

${ }^{2}$ Pontifícia Universidade Católica do Paraná (PUCPR), Brasil, Mestre em Administração (PUCPR), e-mail: nandamoreti.s@gmail.com

\section{RESUMO}

Este artigo analisa a relação entre a marca do empregador - ou employer branding - e o uso de ferramentas de gestão por competências por meio da análise de conteúdo de dados secundários sobre as melhores empresas para se trabalhar do estado do Paraná, do período de 2014 a 2020. A análise abrangeu as quatro melhores empresas de grande porte do Paraná. Os resultados mostraram que há uma relação entre o uso de gestão por competências e uma marca do empregador forte, pois as empresas analisadas utilizam ferramentas de gestão, avaliação, desenvolvimento e reconhecimento para atrair e reter funcionários, sendo este o principal objetivo da marca do empregador.

Palavras-chave: Employer Branding. Gestão por Competências. Marca Corporativa.

\section{ABSTRACT}

This paper analyzes the relation between the Employer Branding and the use of competency management tools through the content analysis of secondary data regarding the best companies to work in the state of Paraná from 2014 to 2020. The analysis covered the four best Paraná large companies. The results showed that there is a relation between the use of competency management and a strong Employer Brand, once the companies analyzed use management, evaluation, development and recognition tools to attract and retain employees, which is the main objective of the Employer Branding.

Keywords: Employer Branding. Competency Management. Corporate Branding. 


\section{INTRODUÇÃO}

Employer Branding, também conhecido como a "marca do empregador" ou a "marca corporativa", se refere a um conceito que usa a abordagem de marketing para a criação de uma marca empregadora única voltada para seus funcionários atuais e potenciais, a fim de atrair e reter os melhores talentos por meio de um pacote de benefícios funcionais, econômicos e psicológicos que são dados a eles e que identificam a organização, em troca do seu trabalho (AMBLER; BARROW, 1996). Tais benefícios denotam a ideia de a organização ser um bom lugar para se trabalhar (PARK, 2013 apud SANTOS, 2017; SULLIVAN, 2004 apud BACKHAUS; TIKOO, 2004), sendo que investir em tais benefícios só faz sentido se houver retenção das pessoas que podem dar o retorno de tal investimento (AMBLER; BARROW, 1996).

Diante da competitividade do ambiente, se torna importante construir uma marca atrativa para as pessoas que detêm know how, dinâmica, dentre outras características difíceis de imitar e replicar, as quais são potenciais fontes de vantagem competitiva (BARNEY, 1991), desta forma, a preocupação em possuir determinadas características não é apenas do candidato, mas também da organização (SANTOS, 2017).

A Employer Branding se relaciona, desta forma, com os recursos humanos, haja vista que estes recursos acrescentam valor para a organização, pois ajudam as empresas a melhorar sua produtividade e a atrair os melhores candidatos, além de promover a retenção e compromisso deles com a organização (SANTOS, 2017).

Dentro do pacote de benefícios atrativos para reter colaboradores está a forma de gestão que a organização utiliza. A gestão por competência, segundo Fernandes (2013) é quando uma organização define e formaliza um conjunto de competências que são esperadas de seus funcionários e as utilizam de forma sistemática ${ }_{2}$ como parâmetro para avaliar e desenvolver suas pessoas, a fim de alinhar as contribuições dos funcionários aos objetivos do negócio.

Tendo em vista os assuntos acima citados, este estudo busca verificar se há relação entre o uso da gestão por competência e uma marca do empregador forte, ou seja, atrativa para seus colaboradores atuais e potenciais.

Os objetivos desse estudo são: a) identificar quais foram as empresas eleitas como as melhores para se trabalhar no estado do Paraná entre os anos de 2014 a 2020; b) analisar,

Revista Expectativa, Toledo/PR, v.20, n. 3, p. 152-168, jul./set., 2021. 
segundo os dados do levantamento da Great Place To Work, do jornal Gazeta do Povo e do site Love Mondays, quais são as principais características dessas empresas; e c) verificar se há uma relação entre a atratividade dessas empresas e o uso da gestão por competência em suas organizações.

O trabalho está organizado da seguinte forma: a seção 2 aborda o referencial teórico utilizado e contém os principais pontos da literatura sobre os temas Employer Branding e Gestão por Competências; na seção 3 são descritos os procedimentos metodológicos utilizados no estudo; a seção 4 apresenta os resultados encontrados na pesquisa e; na seção 5 descrevemse as considerações finais.

\section{REFERENCIAL TEÓRICO}

Nesta seção são apresentados os conceitos de Employer Branding e de Gestão por Competências que serviram como base para a elaboração deste artigo.

\subsection{EMPLOYER BRANDING}

A Employer Branding é um conceito que resulta da unificação de duas disciplinas separadas em um único quadro conceitual, sendo elas "recursos humanos" e "marketing de marca", onde se substitui os "clientes" por "funcionários" (AMBLER; BARROW, 1996), e se refere à uma área de marketing a nível corporativo que possui orientação para stakeholders e não somente para o cliente (BALMER; GRAY, 2003). Este termo, segundo BACKHAUS; TIKOO (2004), sugere a diferenciação de uma empresa de seus concorrentes em relação a suas características como empregadora.

Para Sullivan (2004, apud BACKHAUS; TIKOO, 2004, p. 501), a Employer Branding se refere a "uma estratégia direcionada a longo prazo para gerenciar a conscientização e as percepções de funcionários, potenciais funcionários e partes interessadas em relação a uma determinada empresa", assim tem o intuito de atrair e reter candidatos e assegurar que os funcionários atuais estejam envolvidos na cultura, valores e estratégia da empresa (BACKHAUS; TIKOO, 2004).

Balmer e Gray (2003) argumentam que a Employer Branding é um recurso valioso que pode proporcionar vantagem competitiva, tendo os funcionários como os elementos cruciais

Revista Expectativa, Toledo/PR, v.20, n. 3, p. 152-168, jul./set., 2021. 
para o sucesso e manutenção das marcas corporativas. Ademais, por meio dela, além de atrair funcionários, que se sentem orgulhosos por fazer parte de uma organização, também atrai uma variedade de partes interessadas, como fornecedores, investidores e consumidores, que enxergam na organização uma garantia de qualidade. Assim, ela comunica seus valores, se diferencia dos concorrentes e aumenta a estima e lealdade dos grupos interessados (BALMER, 2001b apud BALMER; GRAY, 2003).

Segundo Balmer (2001a apud BALMER; GRAY, 2003), as características da marca corporativa se respaldam em uma cultura forte, na sua multidisciplinariedade e dimensão que afetam vários grupos de interesse, na sua tangibilidade que envolve a qualidade do produto ou do serviço oferecido, o escopo do negócio, cobertura geográfica, escalas salariais, no "estilo de vida" e nas respostas emocionais aos elementos associados à marca, bem como no compromisso de uma variedade de grupos e redes de partes interessadas.

Segundo Ambler e Barrow (1996) e Balmer e Gray (2003), o conceito de Employer Branding possui similaridade com os seguintes grupos de conceitos: "cultura e identidade corporativa", "marketing interno" e "imagem e reputação corporativa".

A cultura pode ser definida como "os valores que sustentam o propósito e estratégia organizacional ou a identidade corporativa" (AMBLER; BARROW, 1996, p. 188). Desta forma, a cultura do local de trabalho é moldada em torno dos objetivos corporativos, permitindo que a empresa atinja uma cultura única focada em fazer negócios na sua própria maneira e que atue como um guia para que os funcionários moldem seus comportamentos (BACKHAUS; TIKOO, 2004). A identidade corporativa se refere aos atributos distintos de uma organização, abordando questionamentos sobre "o que e quem somos nós", que abrangem, dentre outros, o escopo comercial e a cultura (BALMER; GREYSER, 2003 apud BALMER; GRAY, 2013). A Employer Branding, por sua vez, impacta na cultura e identidade corporativa que contribuem para a lealdade à sua marca (BACKHAUS; TIKOO, 2004).

O marketing interno é responsável pela incorporação das "promessas" feitas aos candidatos na cultura organizacional (FROOK, 2001 apud BACKHAUS; TIKOO, 2004), a fim de desenvolver uma força de trabalho diferenciada que seja comprometida com o conjunto de valores e objetivos organizacionais estabelecidos pela empresa, de modo que caracterize a empresa como empregadora e que seja um recurso difícil para outras empresas imitarem (BACKHAUS; TIKOO, 2004).

Revista Expectativa, Toledo/PR, v.20, n. 3, p. 152-168, jul./set., 2021. 
A imagem e reputação corporativa, por sua vez, afetam a atratividade da organização para potenciais funcionários (BACKHAUS; TIKOO, 2004) e possuem três componentes: competência, consistência e integridade, por meio dos quais a corporação pode ser revelada, compreendida e gerenciada (BALMER; GRAY, 2003). É a imagem da corporação que determina algumas associações da organização em relação aos benefícios funcionais, como salário, benefícios e subsídios, e aos benefícios simbólicos, como aprovação e prestígio social por fazer parte desta organização (BACKHAUS; TIKOO, 2004).

\subsection{GESTÃO POR COMPETÊNCIAS}

A gestão por competências é, segundo Fernandes (2013), um conjunto de competências definido pela organização do que é esperado de seus funcionários e é utilizado de forma sistemática como parâmetro para avaliar e desenvolver suas pessoas, a fim de alinhar as contribuições dos funcionários aos objetivos do negócio.

Essa forma de gestão tem início da década de 1970 e durante os anos foi se aperfeiçoando até chegar ao modelo de Dutra (2001 apud FERNANDES, 2013, p. 73), que "utiliza conceitos de competência, complexidade, espaço ocupacional e agregação de valor como referenciais para organizar as práticas de RH”. Nesse modelo, a noção de competências está relacionada à capacidade e entrega e ao entendimento de que as competências não são estáticas, mas que podem ser desenvolvidas e aprimoradas ao longo do tempo, coincidindo com o movimento de carreira e crescimento nos níveis de complexidade (FERNANDES, 2013).

Para fins deste estudo, utilizamos o conceito de competência apresentado por Fernandes (2013), este que é baseado em estudos anteriores de Dutra (2001, 2004), Fleury e Fleury (2004) e outros autores que escreveram sobre o tema. Competência individual é, portanto, o conjunto de capacidades (conhecimento, habilidades, atitudes e valores) e entregas (contribuição, agregação de valor) que um indivíduo mobiliza e aplica em um determinado contexto profissional.

Ainda, segundo Fernandes (2013), alguns conceitos estão associados ao termo competência, sendo que eles compõem o conjunto de capacidades e entregas do indivíduo. Nas capacidades podemos citar o conhecimento, a habilidade - a destreza em realizar algo manual ou mentalmente, as atitudes ou a predisposição em relação a alguma coisa e os valores, que são

Revista Expectativa, Toledo/PR, v.20, n. 3, p. 152-168, jul./set., 2021. 
os princípios norteadores e que, em um contexto organizacional, estes valores devem estar alinhados aos da organização. Com relação às entregas que o colaborador faz, podemos relacionar os conceitos de potencial, ou seja, a aptidão do indivíduo em realizar suas atividades e os resultados que ele apresenta, medido por meio do alcance das metas estabelecidas (FERNANDES, 2013).

Para medir e avaliar as capacidades e entregas dos colaboradores dentro de uma organização, foram criadas diversas ferramentas que possibilitam aos gestores o acompanhamento e devidos ajustes de acordo com os resultados obtidos. Após uma avaliação, é possível definir, ainda, a necessidade de programas de treinamento e desenvolvimento do corpo de empregados, implicando também em programas de remuneração e sucessão.

Um dos objetivos da gestão por competências é aperfeiçoar os processos de gestão de pessoas, utilizando práticas voltadas ao desenvolvimento e valorização das competências específicas da empresa e promovendo um ambiente de trabalho participativo e saudável que mantenha o colaborador sempre motivado (CARBONE, apud CARBONE, 2015).

\section{PROCEDIMENTOS METODOLÓGICOS}

Para avaliar a relação entre uma marca do empregador forte e o uso de ferramentas de gestão por competências, foram utilizados dados secundários do ranking realizado pela consultoria Great Place to Work, instituição que avalia milhares de empresas ao redor do mundo e certifica as que apresentam melhores ambientes para se trabalhar, além de oferecer serviços de consultoria que visam aumentar o desempenho e os índices de inovação por meio de uma cultura de confiança, além de matérias publicadas no jornal Gazeta do Povo e avaliações de funcionários e ex-funcionários deixadas no site Love Mondays.

O primeiro passo foi fazer a pesquisa no ranking de quais foram as quatro empresas de grande porte, ou seja, aquelas com mais de 1000 funcionários, que foram eleitas as melhores para se trabalhar no estado do Paraná nos anos de 2014 até 2020. Em seguida, foi feita uma pesquisa das avaliações de funcionários e ex-funcionários dessas empresas que foram publicados no site Love Mondays, que passou a se chamar Glassdoor. Os comentários foram codificados e categorizados por meio da análise de conteúdo, a fim de elaborar o gráfico com os principais aspectos pontuados nos comentários.

Revista Expectativa, Toledo/PR, v.20, n. 3, p. 152-168, jul./set., 2021. 
A análise de conteúdo se refere, segundo Bardin (1995), a um conjunto de técnicas de análise das comunicações, que utiliza procedimentos sistemáticos e objetivos de descrição do conteúdo das mensagens. Para compreender o posicionamento das organizações, foram utilizadas as entrevistas de gestores dadas ao jornal Gazeta do Povo que é parceiro na divulgação dos resultados do ranking da Great Place to Work. A partir dessas informações foi possível identificar a existência ou não de uma relação entre o uso da gestão por competências e a força da marca empregadora.

\section{APRESENTAÇÃO E ANÁLISE DOS RESULTADOS}

No Quadro 1 é apresentado o ranking com as quatro melhores empresas de grande porte para se trabalhar no estado do Paraná de acordo com o ranking da Great Place To Work e no Quadro 2 é exposta uma breve descrição sobre estas empresas, com informações do site LoveMondays (n.d.). O Gráfico 1, por sua vez, apresenta os itens de maior relevância segundo os funcionários e ex-funcionários destas empresas, de acordo com comentários publicados no site LoveMondays (n.d.).

Quadro 1- Ranking das melhores empresas para se trabalhar no Paraná

\begin{tabular}{|cccccccc|}
\hline $\begin{array}{c}\text { Posição } \begin{array}{c}\text { Ano } \\
\text { 1. }\end{array} \\
\mathbf{1 0}^{\mathbf{2}}\end{array}$ & Gazin & Gazin & Gazin & Gazin & Gazin & Gazin & Gazin \\
$\mathbf{3 .}^{\mathbf{0}}$ & Volvo & Volvo & Volvo & Apetit & Volvo & Volvo & Apetit \\
$\mathbf{4 .}^{\mathbf{0}}$ & GVT & Apetit & Electrolux & ElectrXolux & Electrolux & Electrolux & Electrolux \\
\hline
\end{tabular}

Fonte: elaborado pelas autoras (2020)

A partir do Quadro 1, pode-se notar que a Gazin se mantém no topo do ranking em todos os anos pesquisados, enquanto a Apetit se manteve entre a segunda e terceira posição no período analisado. A GVT deixa de constar no ranking a partir do ano de 2016, após ser comprada pela Telefónica. Com isso, a Electrolux passa a compor o top quatro do levantamento. Em 2020, a Volvo também deixa de compor o ranking e a Cresol passa a figurar na junto das quatro melhores empresas do estado para se trabalhar.

O Quadro 2, abaixo, apresenta uma breve descrição sobre as empresas, com informações coletadas do site LoveMondays (n.d.). Nele, conseguimos identificar que cada uma das

Revista Expectativa, Toledo/PR, v.20, n. 3, p. 152-168, jul./set., 2021. 
empresas atua em um segmento diferente das demais, sendo que três delas são empresas paranaenses que cresceram ao longo dos anos e duas multinacionais, ambas de origem sueca. Isso mostra que as organizações nacionais também estão comprometidas em obter melhores resultados e a pensar nos funcionários, assim como empresas multinacionais, que trazem consigo a cultura de seu país de origem mais forte e que influenciam diretamente nos valores e ações aplicadas na organização.

Quadro 2 - Descrição das melhores empresas para se trabalhar no Paraná

\begin{tabular}{|c|c|}
\hline Empresa & Descrição \\
\hline Gazin & $\begin{array}{l}\text { Atua no mercado varejista e atacadista de eletrodomésticos, colchões, } \\
\text { estofados, espumas e molas e posto de gasolina. Está há } 46 \text { anos no mercado, } \\
\text { sua sede e o maior de seus centros de distribuição é localizado em Douradina } \\
\text { (PR). Ela possui filiais em diversos estados brasileiros, atendendo todas as } \\
\text { regiões do país. }\end{array}$ \\
\hline Volvo & $\begin{array}{l}\text { Fundada em 1927, a Volvo é uma empresa sueca que produz e comercializa } \\
\text { veículos comerciais, sendo a maior fabricante de caminhões do mundo. No } \\
\text { Brasil, chegou no fim dos anos } 70 \text {, com a criação de ônibus, micro-ônibus, } \\
\text { equipamentos para construção e caminhões para a todo o país. Atualmente, } \\
\text { possui concessionárias em todo o território nacional. Em todo o mundo, } \\
\text { possui aproximadamente } 100 \text { mil funcionários. }\end{array}$ \\
\hline Apetit & $\begin{array}{l}\text { Se consolidou ao longo de mais de } 25 \text { anos como uma das melhores empresas } \\
\text { de alimentação corporativas do Brasil. A empresa, que começou em } \\
\text { Londrina em 1989, servindo apenas } 13 \text { refeições diárias e com somente um } \\
\text { funcionário, hoje se orgulha de atuar em quase todos os estados brasileiros, } \\
\text { produzindo mais de } 100 \text { mil refeições por dia, com um quadro de } \\
\text { aproximadamente } 2.000 \text { colaboradores espalhados pelas centenas de } \\
\text { restaurantes que administra. }\end{array}$ \\
\hline GVT & $\begin{array}{l}\text { Foi uma operadora de telecomunicações brasileira encerrada no dia } 15 \text { de } \\
\text { abril de } 2016 \text {, ao ser adquirida pela Telefónica. Surgiu em } 2000 \text { como } \\
\text { resultado de um consórcio formado pela holandesa Global Village Telecom } \\
(78 \%) \text { e as norte-americanas ComTech Communications Technologies } \\
(20 \%) \text { e RSL }(2 \%) \text {. }\end{array}$ \\
\hline Electrolux & $\begin{array}{l}\text { Líder mundial em eletrodomésticos e aparelhos de uso profissional, a } \\
\text { Electrolux está presente em mais de } 150 \text { países. Sua trajetória em quase } 100 \\
\text { anos de existência se traduz em desenvolvimento, inovação, design moderno } \\
\text { e funcionalidade. Entre os produtos da marca, há uma extensa quantidade de } \\
\text { modelos de refrigeradores, freezers, lavadoras, microondas e fornos, além de } \\
\text { condicionadores de ar e cooktops. A Electrolux realiza constantes pesquisas } \\
\text { em busca de novas tendências e tecnologia, para atender às aspirações e } \\
\text { desejos de cada um de seus clientes. }\end{array}$ \\
\hline
\end{tabular}

Revista Expectativa, Toledo/PR, v.20, n. 3, p. 152-168, jul./set., 2021. 


\begin{tabular}{|l|l|}
\hline Cresol & $\begin{array}{l}\text { É uma cooperativa de crédito fundada em } 1995 \text { em Francisco Beltrão, } \\
\text { interior do Paraná. Atua no ramo de serviços financeiros e de crédito e hoje } \\
\text { está presente em dez estados brasileiros. Trabalha com foco no atendimento } \\
\text { personalizado, para fornecer soluções financeiras que geram } \\
\text { desenvolvimento dos cooperados, de seus empreendimentos e de toda } \\
\text { comunidade. }\end{array}$ \\
\hline
\end{tabular}

Fonte: elaborado pelas autoras (2021)

O Quadro 3, por sua vez, apresenta um resumo das principais ações que são ou foram adotadas por estas empresas. Desta forma, este quadro elenca o que se considera importante para o tratamento com os funcionários, na visão das empresas.

Em termos gerais, pode-se perceber vários aspectos em comum dentre estas empresas, sendo os principais: a preocupação em manter uma comunicação clara dentro da organização tanto em relação as metas do trabalho em si, como sobre a cultura e ideologia da empresa; a formulação de processos de recrutamento e seleção visando por pessoas com objetivos e valores em comum com os da empresa e; a preocupação com o bem-estar do funcionário, seja por meio do fornecimento de benefícios e recompensas salariais, ou pela possibilidade de desenvolvimento profissional dentro da empresa através de cursos e treinamentos.

Quadro 1 - Resumo das principais ações adotadas pelas empresas

\begin{tabular}{|c|l|}
\hline Empresa & \multicolumn{1}{c|}{ Ações adotadas } \\
\hline \multirow{5}{*}{ Gazin } & - Desenvolvimento de uma política clara de gestão de pessoas; \\
& - Preocupação em colocar a satisfação dos clientes - internos e externos - \\
em primeiro lugar; & - Desenvolvimento de uma comunicação clara para a equipe sobre \\
intenções e ideologia; \\
- Colocação do cliente como centro de referências para ações e \\
comportamento dos funcionários; \\
- Desenvolvimento, orientação e trabalho com uma cultura de alcance de \\
metas e objetivos; \\
- Cuidado na seleção e desenvolvimento dos membros da equipe; \\
- Fornecimento de feedback aos funcionários de modo que saibam com \\
clareza onde estão acertando e/ou errando; \\
- Compartilhamento de metas e informações sobre a empresa e celebração \\
das conquistas.
\end{tabular}

Revista Expectativa, Toledo/PR, v.20, n. 3, p. 152-168, jul./set., 2021. 


\begin{tabular}{|c|c|}
\hline Volvo & $\begin{array}{l}\text { - Demonstração de paixão ao propósito da empresa de prover prosperidade } \\
\text { para toda a sociedade, através de soluções para o transporte; } \\
\text { - Consideração das pessoas como centro de tudo que é feito na empresa; } \\
\text { - Recrutamento e seleção de pessoas cuja política incentiva a diversidade, } \\
\text { apoiada na identificação de talentos; } \\
\text { - Promoção de melhorias na comunicação, que abrange grupos com } \\
\text { reuniões semanais, criação de comissão de fábrica para estreitar a relação } \\
\text { funcionário-empresa; } \\
\text { - Criação equipes auto gerenciáveis e programas que englobam a política } \\
\text { de qualidade de vida, com um olhar minucioso para as diversas práticas } \\
\text { que envolvem todos os aspectos do trabalhador: jornada flexível, promoção } \\
\text { de alimentação saudável, assistência médica domiciliar de urgência, } \\
\text { programa individual de home-office pós licença maternidade, atividades } \\
\text { sociais e programa de preparação para aposentadoria, além dos programas } \\
\text { corporativos educacionais, como curso de idioma, programas de } \\
\text { voluntariado, planejamento familiar e de investimentos e programas de } \\
\text { desenvolvimento de lideranças. }\end{array}$ \\
\hline Apetit & $\begin{array}{l}\text { - Investimento no cuidado com as pessoas; } \\
\text { - Promoção da segurança e do bem-estar de todos; } \\
\text { - Asseguramento de todos os direitos do trabalhador; } \\
\text { - Promoção de benefícios corporativos como auxílio alimentação, plano de } \\
\text { saúde e odontológico, desconto em instituições de ensino e fomento à } \\
\text { capacitação profissional gratuita por meio da Universidade Corporativa } \\
\text { Apetit (UNIAP); } \\
\text { - Disponibilização de programas de ginástica laboral; } \\
\text { - Promoção de campanhas de conscientização e engajamento que } \\
\text { estimulam o sentimento de pertença dos colaboradores. }\end{array}$ \\
\hline GVT & $\begin{array}{l}\text { - Modelo de gestão de desempenho que leva em consideração a orientação, } \\
\text { feedback, desenvolvimento e reconhecimento, de modo a haver clareza } \\
\text { sobre o que se espera do colaborador, monitoramento do andamento das } \\
\text { suas atividades e de sua evolução enquanto profissional e avaliação de seus } \\
\text { resultados, reconhecendo e recompensando suas conquistas; } \\
\text { - Fornecimento de mais de } 30 \text { benefícios diversos para o funcionário, como } \\
\text { plano de saúde e odontológico, auxílio creche, previdência privada, seguro } \\
\text { de vida, transporte, refeição e jornada flexível. }\end{array}$ \\
\hline Electrolux & $\begin{array}{l}\text { - Fornecimento de feedback por parte dos líderes, permitindo que cada um } \\
\text { monte seu plano de desenvolvimento pessoal, concentrando } 70 \% \text { nas } \\
\text { experiências do ambiente de trabalho, } 20 \% \text { nas interações com os colegas e } \\
10 \% \text { na capacitação técnica e cursos de pós-graduação; } \\
\text { - Capacitação das pessoas por meio da "Escola de Manufaturas"; } \\
\text { - Desenvolvimento de habiliadades de profissionais com perfis de líderes } \\
\text { por meio do "Desenvolvimento de Lideranças"; } \\
\text { - Adoção de boas práticas de gestão relacionadas ao local de trabalho, } \\
\text { como: Gerenciamento recorrente de questões relacionadas ao Local de } \\
\text { Trabalho; Manutenção de procedimentos operacionais padrão que incluem } \\
\text { lembretes regulares sobre tópicos relacionados ao Local de Trabalho; } \\
\text { Estabelecimento de um sistema de comunicação formal, tal como um } \\
\text { comitê de queixas de trabalhadores ou um sistema de denúncias em que os } \\
\text { funcionários podem levantar questões de interesse e; Introdução e } \\
\text { aplicação de padrões mais rigorosos do que os exigidos na Política do } \\
\text { Local de Trabalho/Norma para Fornecedor. }\end{array}$ \\
\hline
\end{tabular}

Revista Expectativa, Toledo/PR, v.20, n. 3, p. 152-168, jul./set., 2021. 


\begin{tabular}{|l|l|}
\hline & - Desenvolvimento de ações com os colaboradores, com foco na \\
valorização profissional; \\
- Preocupação com bem-estar dos colaboradores e cooperados; \\
- Criação do sentimento de envolvimento nas ações da cooperativa, através \\
de reconhecimento por tempo de empresa, feedback das \\
atividades e confraternizações; \\
- Processo de recrutamento e seleção visando atrair profissionais com \\
capacidade para agregar valor e sintonizar com a missão, visão e valores \\
das Entidades do Sistema Cresol Baser. \\
- Fornecimento de benefícios diversos aos colaboradores, como: vale \\
alimentação, seguro de vida, previdência privada e plano de saúde.
\end{tabular}

Fonte: elaborado pelas autoras (2021)

O Gráfico 1 apresenta os itens de maior relevância segundo os funcionários e exfuncionários destas empresas, de acordo com a análise de conteúdo realizada a partir de comentários publicados no site LoveMondays (n.d.). Ou seja, neste gráfico, são elencados os itens mais importantes para a satisfação no trabalho, na visão dos funcionários.

Para a construção deste gráfico, os comentários foram codificados e categorizados conforme a mensagem que os funcionários passavam com o seu conteúdo. A partir disto, observou-se a frequência que cada categoria esteve presente, assim pode-se notar que várias categorias foram citadas por funcionários diferentes, demonstrando uma percepção comum sobre seu ambiente de trabalho.

Desta forma, o Gráfico 1 demonstra que itens como oportunidade de crescimento, treinamento, respeito, pacote de benefícios, valorização dos funcionários, bom ambiente de trabalho e remuneração compatível com o mercado, são os que mais se destacaram como importantes na percepção dos funcionários destas empresas, reafirmando o que pode ser encontrado na literatura sobre Employer Branding, onde se revela a preocupação em manter boas condições de trabalho a fim de manter a reputação da organização como um lugar atrativo para os melhores candidatos, reforçando uma imagem positiva da organização. Essas características apontadas pelos empregados também são encontradas na gestão por competências, que trata da remuneração para engajar, motivar e valorizar as pessoas que já estão na empresa, por isso é importante ter o olhar do marketing interno para a retenção desses funcionários. 
Gráfico 1 - Aspectos positivos apontados por funcionários e ex-funcionários

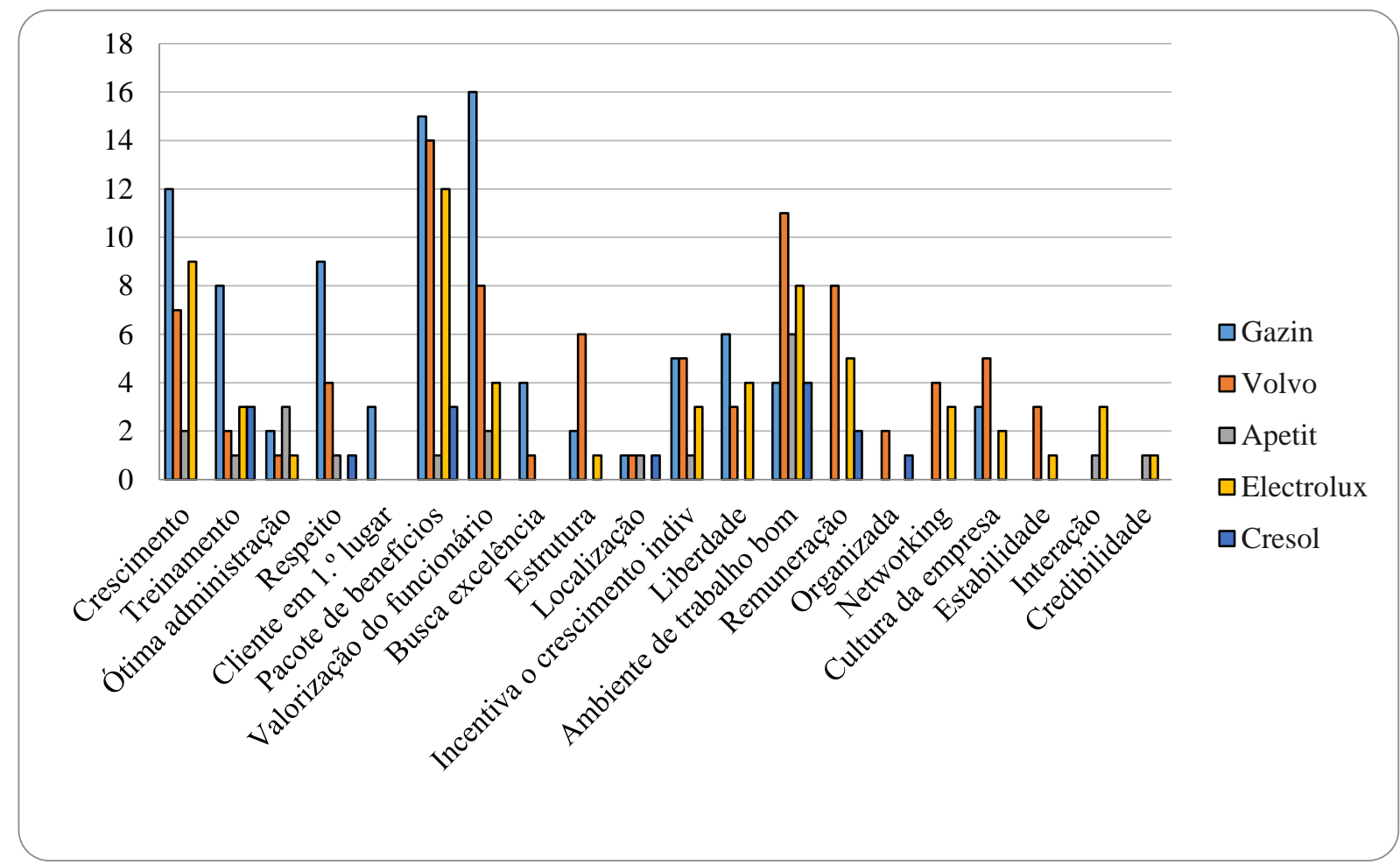

Fonte: Elaborado pelas autoras (2021).

A presidente da Apetit, empresa posicionada em segundo lugar no ranking 2017, afirma que o sentimento de pertença decorrente da comunicação interna eficiente é um dos principais motivos para a boa colocação e visibilidade para potenciais empregados (GAZETA DO POVO, 2017). Além disso, dentre os destaques na análise dos comentários feitos por seus funcionários estão a consideração de que o ambiente de trabalho é bom, o que neste ponto inclui aspectos como ser um ambiente amigável, além do fato de ser considerado um ambiente que promove oportunidade de crescimento. Tanto nas leituras sobre Employer Branding como sobre gestão por competências, é citada a importância da comunicação ou marketing interno no desenvolvimento de uma atuação comprometida com os objetivos da organização, bem como os seus valores (BACKHAUS; TIKOO, 2004). Desta forma, estes são pontos que contribuem tanto para a marca da empresa como um fator atrativo para novos funcionários, bem como para a manutenção do quadro funcional atual, por meio da gestão por competências, haja vista a sua preocupação em promover um ambiente participativo e motivado.

A afirmação de Hilgo Gonçalves, embaixador do Great Place to Work e diretor da regional do Paraná (GAZETA DO POVO, 2017), “as empresas que estão na lista [...], geram

Revista Expectativa, Toledo/PR, v.20, n. 3, p. 152-168, jul./set., 2021. 
um retorno duas vezes maior que as demais, são mais inovadoras e eficientes, geram melhor experiência dos clientes e maior retenção dos seus talentos, logo, a performance é mais sustentável", também é consistente com o que é encontrado na literatura. Segundo o modelo de Dutra (2001, 2004 apud FERNANDES, 2013), as entregas também fazem parte da gestão por competências, pois quando os empregados conseguem agregar valor às suas atividades, eles contribuem positivamente para um melhor desempenho da organização e, consequentemente, melhores resultados no mercado.

Estar entre as melhores para se trabalhar é a principal explicação para a fama de empresas como a Volvo, inclusa no ranking nos quatro anos mencionados, que recebe em torno de 300 mil currículos por ano, que tem dentre seus principais atrativos itens como treinamento, participação nos lucros, pacote de benefícios que inclui educação e saúde e possibilidade de atuar em outros países (GAZETA DO POVO, 2013).

A Gazin também possui atrativos como universidade corporativa, bolsas de estudo, programas de desenvolvimento, práticas esportivas, treinamentos e, além disso, incentivos como viagens ofertadas para funcionários que cumprem metas (GAZETA DO POVO, 2013). Nesse aspecto, podemos perceber a relação de ser uma empresa atrativa para os colaboradores e o uso de ferramentas de gestão por competências na área de treinamento e desenvolvimento, primando pela valorização dos empregados e qualificação para futuras movimentações ou ascensões de carreira.

Liderando o ranking das grandes empresas do Paraná, a gerente de desenvolvimento humano da Gazin acredita que isso se deve principalmente à empresa se manter fiel aos seus valores e buscar pessoas que compartilhem deles (GAZETA DO POVO, 2020). Ter uma imagem forte e consolidada no mercado, que valoriza as pessoas e as desenvolve faz com que a empresa seja atrativa, reforçando a relação positiva entre aplicar a gestão por competências e firmar uma boa marca empregadora.

Outra empresa ocupando as primeiras posições no ranking, a Electrolux investe em práticas como a qualificação operacional e de lideranças, além de oportunizar a construção da carreira na empresa e possibilitar aos colaboradores experiência de atuação nas suas unidades ao redor do mundo (GAZETA DO POVO, 2017). A aplicação de avaliações de desempenho e feedbacks permite a realização de um plano de desenvolvimento individual dos empregados da Electrolux, da mesma forma em que encontramos no conceito de avaliação profissional dentro

Revista Expectativa, Toledo/PR, v.20, n. 3, p. 152-168, jul./set., 2021. 
da gestão por competências. Essa ferramenta, se bem utilizada, traz benefícios para ambos os lados, pois permite ao colaborador se qualificar e se sentir valorizado pela organização, que, por sua vez, fideliza os funcionários e aprimora o desempenho das tarefas.

Um ponto levantado por funcionários da Electrolux nos comentários publicados no site LoveM (n.d), é o de terem maior interação entre as áreas, o que colabora para uma melhor comunicação entre os setores, além de promover a inovação e melhorar o desempenho das equipes. Esses são fatores encontrados em ambas as literaturas, seja para fortalecer a marca do empregador com seus funcionários ou como uma ferramenta de gestão por competência.

Para os colaboradores da Cresol, os principais aspectos positivos da organização são a oferta de cursos e treinamentos, um bom ambiente de trabalho e o pacote de benefícios. Por outro lado, aparece como ponto de melhoria oferecer um salário compatível com o mercado e oferecer mais oportunidades de crescimento na organização. Dentro do que foi apontado como bom na empresa, temos uma característica da gestão por competências, a oferta de treinamento para desenvolver as pessoas, e um aspecto da marca empregadora, o ambiente de trabalho agradável, que podem ser fatores que levaram a cooperativa figurar no ranking entre as melhores empresas para se trabalhar no Paraná, considerando o porte.

\section{CONSIDERAÇÕES FINAIS}

Como mencionado anteriormente, o conceito de Employer Branding aborda o uso do marketing para a criação de uma marca empregadora forte voltada para os funcionários com o objetivo de atrair e manter os melhores talentos na organização (AMBLER; BARROW, 1996), já a gestão por competências é um conjunto das capacidades e entregas dos colaboradores utilizado como parâmetro para avaliar e desenvolver as pessoas com a finalidade de alinhar essas competências com os objetivos da organização (FERNANDES, 2013).

Diante do exposto, após a análise dos dados das melhores empresas para se trabalhar no período de 2014 a 2020, é possível perceber a relação entre as empresas possuidoras de uma marca empreendedora forte com o uso das ferramentas da gestão por competências, tendo em vista a seriedade com que estes itens têm sido abordados pelas empresas tidas como as melhores para se trabalhar, o que faz com que elas reforcem sua imagem de boa empregadora e melhorem

Revista Expectativa, Toledo/PR, v.20, n. 3, p. 152-168, jul./set., 2021. 
seu desempenho por capacitarem e desenvolverem os talentos que possuem dentro de suas organizações.

Cabe mencionar que esta pesquisa não abrange maiores detalhes que poderiam ser obtidos através de dados primários e com um acompanhamento próximo a estas organizações, por meio de entrevistas a gestores e funcionários que fornecessem dados mais direcionados ao escopo do questionamento da pesquisa, sendo que isto poderia ser uma contribuição de pesquisas futuras.

Além disso, pode-se sugerir pesquisas sobre quais elementos e características das empresas são mais bem vistas pelos funcionários num período subsequente ao estudado nesta pesquisa, a fim de considerar se, depois de um período de crise, como o da pandemia do Covid19, as prioridades se mantiveram as mesmas ou houve mais preocupação com outros novos aspectos não considerados anteriormente.

\section{REFERÊNCIAS}

AMBLER, Tim; BARROW, Simon. The employer brand. Journal of brand management, v. 4, n. 3, p. 185-206, 1996.

APETIT. Apetit é a melhor empresa de alimentação corporativa para se trabalhar no Brasil. 2016. Disponível em: https://bityli.com/FiS1M. Acesso em: 16 mar. 2021.

AUTOMOTIVE BUSINESS. Volvo: gestão de RH deve manter ações de sucesso. 2013. Disponível em: http://www.automotivebusiness.com.br/noticia/17006/volvo-gestao-de-rhdeve-manter-acoes-de-sucesso. Acesso em: 16 mar. 2021.

BACKHAUS, Kristin; TIKOO, Surinder. Conceptualizing and researching employer branding. Career development international, 2004.

BALMER, John MT; GRAY, Edmund R. Corporate brands: what are they? What of them?. European journal of marketing, 2003.

\section{BLOG GAZIN ATACADO. Lições da Gazin - a $5^{\mathbf{a}}$ colocada no prêmio Great Place to}

Work. 2014. Disponível em: https://blog.gazinatacado.com.br/licoes-da-gazin-a-5a-colocadano-premio-great-place-to-work/. Acesso em: 16 mar. 2021.

CARBONE, Pedro Paulo. Gestão por competência e educação corporativa: caminhos para o desenvolvimento de competências. Inclusão Social, v. 7, n. 1, 2013. 
CASTRO, Fabiana. Gestão de Desempenho GVT. 2014. 31 slides. Disponível em: https://issuu.com/amchambrasil/docs/fabiana_castro_gest_o_de_desempenh. Acesso em: 17 mar. 2021.

CRESOL. Cresol está entre as melhores empresas para trabalhar no Paraná. 2019.

Disponível em: https://cresol.com.br/cresol-est-entre-as-melhores-empresas-para-trabalharno-paran-2398/. Acesso em: 16 mar. 2021.

CRESOL. Agronegócio: Cresol está entre as dez maiores e melhores empresas para trabalhar no Brasil. 2020. Disponível em: https://cresol.com.br/agronegocio-cresol-esta-entre-as-dezmelhores-empresas-para-trabalhar-no-brasil/. Acesso em: 16 mar. 2021.

ELECTROLUX. Diretriz do Local de Trabalho da Electrolux. 2018. Disponível em: https://www.electroluxgroup.com/en/wp-content/uploads/sites/2/2010/12/group-workplacedirective-2018-portuguese-brazil.pdf. Acesso em: 16 mar. 2021.

FERNANDES, Bruno. Gestão Estratégica de Pessoas: com foco em competências. Elsevier Brasil, 2013.

GAZETA DO POVO. Melhores empresas 2013. 2013. Disponível em:

http://www.gazetadopovo.com.br/economia/especiais/melhores-empresas/2013/. Acesso em: 14 jan. 2018.

GAZETA DO POVO. Melhores empresas 2016. 2016. Disponível em:

http://www.gazetadopovo.com.br/economia/especiais/melhores-empresas/2016/. Acesso em: 14 jan. 2018.

GAZETA DO POVO. Funcionários e comunidade envolvidos. 2014. Disponível em: http://www.gazetadopovo.com.br/economia/especiais/melhores-empresas/2014/funcionariose-comunidade-envolvidos-egwx52igfb0vcskujj4nkj5n2. Acesso em: 25 ago. 2020.

GAZETA DO POVO. O segredo das 50 melhores empresas para trabalhar no Paraná em 2017. 2017. Disponível em: https://bityli.com/MrDnj. Acesso em: 25 ago. 2020.

GAZETA DO POVO. Segredo do tetra é reconhecimento. 2014. Disponível em: http://www.gazetadopovo.com.br/economia/especiais/melhores-empresas/2014/segredo-dotetra-e-reconhecimento-egws797uwhqo31padl37p0fgu. Acesso em: 25 ago. 2020.

GAZETA DO POVO. Veja a lista das empresas vencedoras do Great Place to Work. 2014. Disponível em: https://bityli.com/ciVvm. Acesso em: 25 ago. 2020.

GAZETA DO POVO. Gazin completa nove anos como a melhor empresa para se trabalhar no Paraná. 2020. Disponível em:

https://www.gazetadopovo.com.br/vozes/parana-sa/gazin-nono-ano-melhor-empresa-para-setrabalhar-parana/. Acesso em: 09 mar. 2021. 
GAZETA DO POVO. Investimento na qualificação dos profissionais é prioridade na Electrolux. 2017. Disponível em: https://bityli.com/sXGO4. Acesso em: Acesso em 16 mar. 2021.

GLASSDOOR. Benefícios e vantagens dos funcionários da GVT. Disponível em: https://www.glassdoor.com.br/Benef\%C3\%ADcios/GVT-Brasil-Benef\%C3\%ADciosEI_IE640865.0,3_IL.4,10_IN36.htm. Acesso em: 17 mar. 2021.

GREAT PLACE TO WORK. Ranking Paraná. 2015. Disponível em: http://gptw.com.br/ranking/parana-2015.htm. Acesso em: 14 jan. 2018.

GREAT PLACE TO WORK. Ranking Paraná. 2017. Disponível em: http://www.greatplacetowork.com.br/ranking/parana-2017-grandes.htm. Acesso em: 14 jan. 2018.

GREAT PLACE TO WORK. Certificação. Disponível em: http://www.gptw.com.br/certificacao. Acesso em: 14 jan. 2018.

GREAT PLACE TO WORK. Ranking Paraná. 2018. Disponível em: https://gptw.com.br/ranking/melhoresempresas $/$ ano $=2018 \&$ tipo $=$ Regional $\&$ ranking $=$ parana $\&$ corte $=1000$ ouMaisFuncionarios . Acesso em: 08 mar. 2021.

GREAT PLACE TO WORK. Ranking Paraná. 2019. Disponível em: https://gptw.com.br/ranking/melhoresempresas/?ano=2019\&tipo=Regional\&ranking=parana\&corte=Grandes. Acesso em: 08 mar. 2021.

GREAT PLACE TO WORK. Ranking Paraná. 2020. Disponível em: https://gptw.com.br/ranking/melhoresempresas $/$ ano=2020\&tipo=Regional\&ranking $=$ Paran\%C3\%A1\&corte $=$ Grandes. Acesso em: 09 mar. 2021.

GURNASKI, Maria Polliana; BORGES, Ceyça Lia Palerosi. Políticas de gestão de pessoas: um estudo de caso sobre a percepção motivacional dos colaboradores da cooperativa Cresol de Laranjeiras do Sul/PR. Revista de Ciências Empresariais da UNIPAR, v. 21, n. 1, 2020.

LOVE MONDAYS. Disponível em: https://www.lovemondays.com.br/. Acesso em: 09 fev. 2018 .

SANTOS, João Nuno Pinto dos. Employer branding como mecanismo de atração e retenção de Talento: o caso da Michael Page. 2017. 77f. Dissertação (Mestrado em Gestão) - Universidade Católica Portuguesa, Porto-Portugal, 2017.

VOLVO SALA DE IMPRENSA. Volvo: mais uma vez a melhor para trabalhar no setor automotivo. 2019. Disponível em: https://saladeimprensavolvo.com.br/releases/volvo-maisuma-vez-a-melhor-para-trabalhar-no-setor-automotivo. Acesso em: 16 mar. 2021. 